\title{
Telepresence with Hologram Effect: Technological Ecosystem for Distance Education
}

\author{
Carla Victoria Ramirez-Lopez ${ }^{1}\left({ }^{10}\right.$, Leticia Castano ${ }^{1}\left(\mathbb{D}\right.$, Patricia Aldape $^{1}\left(\mathbb{D}\right.$ and Santa Tejeda ${ }^{2, *}$ \\ 1 Vice-Rectory Educational Innovation and Academic Norm, Tecnologico de Monterrey, Monterrey 64849, \\ Mexico; carla.ramirez@tec.mx (C.V.R.-L.); lcs@tec.mx (L.C.); patricia.aldape@tec.mx (P.A.) \\ 2 School of Engineering and Sciences, Institute for the Future of Education, Tecnologico de Monterrey, \\ Monterrey 64849, Mexico \\ * Correspondence: stejeda@tec.mx
}

check for

updates

Citation: Ramirez-Lopez, C.V.; Castano, L.; Aldape, P.; Tejeda, S. Telepresence with Hologram Effect: Technological Ecosystem for Distance Education. Sustainability 2021, 13 , 14006. https://doi.org/10.3390/ su132414006

Academic Editors: María

Soledad Ramírez Montoya,

Ebba Ossiannilsson, Arturo Molina

Gutiérrez and Jane-Frances Agbu

Received: 30 October 2021

Accepted: 10 December 2021

Published: 18 December 2021

Publisher's Note: MDPI stays neutral with regard to jurisdictional claims in published maps and institutional affiliations.

Copyright: (c) 2021 by the authors. Licensee MDPI, Basel, Switzerland. This article is an open access article distributed under the terms and conditions of the Creative Commons Attribution (CC BY) license (https:// creativecommons.org/licenses/by/ $4.0 /)$.

\begin{abstract}
One of the most significant challenges of telepresence distance education is to bring the professor and the students closer together in a synchronistic educational experience where the professor is perceived as anatomically proportionate. Telepresence, an educational technology ecosystem using holograms, offers a way to solve this technological challenge. Our mixed exploratory research investigating this methodology had two purposes: (1) propose the key elements to teach distance courses synchronously in an educational technology ecosystem, and (2) demonstrate the technological, didactic practices that result in positive student learning outcomes in several specified courses. This methodology included applying a student questionnaire to collect their perceptions of the educational experience. The scores and written comments from the questionnaire were analyzed using Grounded Theory. On a Likert scale from 1 to 5, the students scored their educational experience, attaining a mean of 4.05 . The positive perception affirmed that they valued: (a) recreating the natural dynamics of face-to-face classes, where the students perceived their professors as being physically present in the classroom; (b) professors renowned in their disciplines; (c) professor-student and campus and intercampus learning community interactions, and, finally, (d) class design and content. The main conclusions of this research were that students positively perceived the "wow" effect of the technology, feeling comfort, amazement, interest, and engagement. In addition, we found that professors and keynote speakers with excellent pedagogical skills and experts in their disciplines were well appreciated. Key elements for the success of the experience were professor-student, campus, and intercampus interactions and the quality of the technological and communication infrastructure.
\end{abstract}

Keywords: telepresence; holographic effect; educational technology; educational innovation; higher education; innovative practices; Education 4.0

\section{Introduction}

Current challenges have led to the search for new paths in education. The evolution in learning means that students need real experiences, new learning methods, and skills with the cutting-edge technology used in industry. Three trends in Education 4.0 related to educational innovation to be addressed are (i) students deciding the best method for learning, (ii) innovations in current learning tools, and (iii) use of digital tools and emerging ICTs [1].

In addition, the authors have identified three main challenges of distance learning education. These are as follows:

(a) Make the students feel that their teacher is close to them. The teacher's presence is important in creating a learning environment that supports the students and attend their needs. The construction of an active learning community greatly influenced the course delivery and the quality of the learning process [2]. Students expected their teachers to check their comprehension and provide informal feedback regularly. 
In face-to-face classes or traditional correspondence courses, they perceived established avenues to keep them updated on progress but felt this was lacking in the videoconference course [3].

(b) Provide the same immediate feedback to the distance-learning students that occurs in the face-to-face classes. Students wanted to receive specific guidance on correcting their papers and continuous and detailed feedback rather than general feedback at the end of the process. The researchers also found that the teacher's presence is essential. Their feedback to students reinforces the learning process; students can feel helpless without feedback [2]. There are also other factors directly related to videoconferencing, such as reluctance to use the microphone, difficulties seeing demonstrations, and passivity when looking at the screen [4].

(c) Grant students access to their professors similar to face-to-face classes. The students expressed that this was not achieved through a traditional videoconference or an online course. The students receive less support from lecturers when they interact online. Students need lecturers' help, but lecturers interact minimally with students online; thus, they are not supportive [5]. Blended synchronous learning still needs better student engagement and involvement in instructional activities. Presence alone in an online environment does not mean that students are actively engaged in the learning process. Blended synchronous learning supported by videoconferencing lacks provisions for online students to be fully immersed in the environment. The online students could only see what the cameras captured [6]. Students perceived videoconferencing as a challenging learning environment. Even in the absence of significant differences in examination performance and student satisfaction rates, students perceived inequities in learning experiences between campuses [4].

These challenges inspired professors (designers) at Tecnologico de Monterrey to design the Telepresence with Hologram Effect, initially called "Professor Avatar." The designers integrated existing educational technology on the market to produce the hologram effect similar to the Pepper's ghost effect that has been used to generate "three-dimensional" projections of virtual objects or people in a real environment. In the Pepper's ghost effect, the object's reflection is the principle behind it. When a light beam strikes an object's surface, it splits into two waves: one is transmitted through the object body, and the other is reflected $[7,8]$. The research designers implemented the technology in classes by transmitting the professor's image from one campus to another. The technology included (a) videoconferencing systems to generate audio in real-time and (b) robots that supported the distance professor. The robots could move around the classroom and approach the teams working collaboratively.

\subsection{Technological Ecosystem for the Telepresence with Hologram Effect Model}

In 2017, a team of developers investigated evidence in publications where telepresence resulted in a different experience. The developers found that telepresence with a hologram made the students feel closer to the teacher more significantly than traditional videoconferences. With the hologram effect, the students saw their teacher in the anatomically correct size and could interact with him or her in real time, thus achieving telepresence. Pelet et al. described this phenomenon as a perceptual illusion of being present without feeling mediated by technology [9]. This feeling can also be achieved with other media and contexts. However, the students reported feeling focused and immersed in the experience. This sensation is described in the literature as the state of flow $[9,10]$. Flow is a psychological state characterized by an intrinsically pleasant, optimized experience. Characteristics also include intense commitment, a distorted sense of time, loss of self-awareness, and increased motivation. In this psychological state, the person feels simultaneously cognitively efficient, motivated, and happy. They become entirely absorbed in what they are doing. To achieve these effects in our telepresence courses, the developers relied on cutting-edge technology and well-known pedagogical strategies in the academic community [11]. 
To recreate a face-to-face educational environment in distance learning lacking the physical presence of the professor, the developers created the Technological Ecosystem for the Telepresence with Hologram Effect Model (see Figure 1), which included the pedagogical strategies that allowed students to have a hybrid experience. In this hybrid experience, they take face-to-face classes with their classmates. However, their professors are distant but enrich their learning by projecting themselves in the anatomically correct size (life-sized). The presential classmates in different cities interact simultaneously.

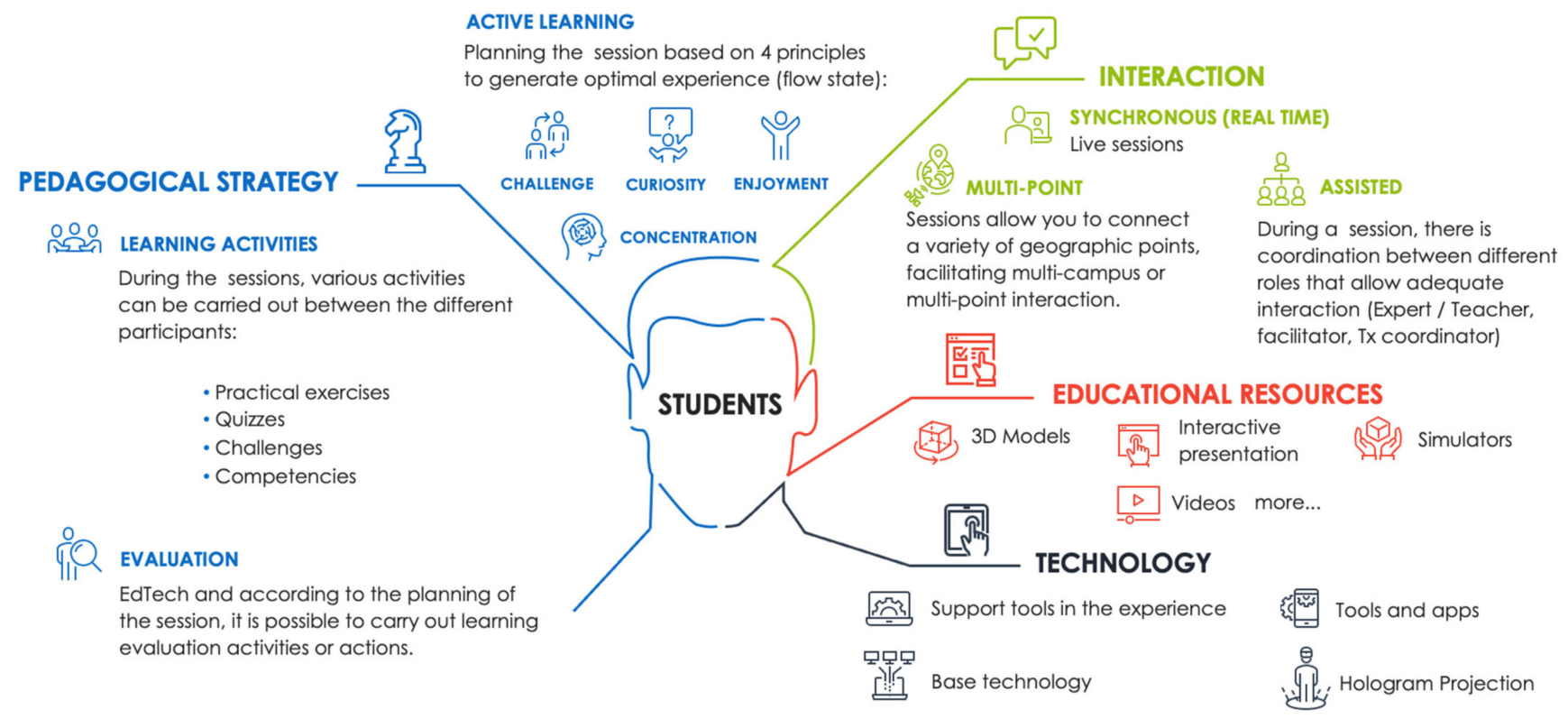

Figure 1. Technological Ecosystem for the Telepresence with Hologram Effect Model.

All these tools combine to form an educational scenario where technology becomes a vehicle for transmitting educational experiences. For this educational experience, the developers integrated four main components, as described below.

\subsubsection{Pedagogical Strategy}

Through active learning, students carry out various contextual activities to build their knowledge. They engage in learning through activities and discussions in class instead of passively listening to an expert. Active learning emphasizes higher-order thinking for analysis, synthesis, and evaluation; it often involves group work [12-14].

In the Telepresence with Hologram Effect Model, the first strategy is selecting the best teachers. Great teachers should be in the projections, prepared and motivated to encourage the students to learn, adopt positive attitudes towards the subject, and collaborate with their classmates [15].

The second strategy is planning. In designing each synchronous session, professors should make a guideline or script for developing the session, dividing it into activity segments with their respective resources and times. The integration of holographic technology in the teaching process is part of a worldwide educational innovation reform and should be accompanied by careful planning and understanding of the dynamics for its integration into classrooms $[15,16]$.

Classroom scripts may include individual work (e.g., writing a synthesis, reading a paper), small group work (e.g., peer editing, collaborative research activities), or plenary activities (e.g., introductory lectures, debriefing). Different types of activities might be necessary to integrate individuals into a collaboration to ensure that the collective unit learns [17].

The phases of the guideline or script should correlate to the four stages of designing a learning experience [18], as shown in Table 1. 
Table 1. Class design phases and segments.

\begin{tabular}{|c|c|c|}
\hline Phase & Segment & Academic Intervention \\
\hline Engagement & Icebreaker & $\begin{array}{l}\text { Beginning the topic, the professor captures } \\
\text { the students' attention and presents the } \\
\text { learning objectives. }\end{array}$ \\
\hline Informing & Share knowledge & $\begin{array}{l}\text { The professor transmits knowledge to the } \\
\text { students through different digital } \\
\text { educational resources, such as interactive } \\
\text { presentations, videos, and specific tools. }\end{array}$ \\
\hline $\begin{array}{l}\text { Individual } \\
\text { practice }\end{array}$ & Interactive activities & $\begin{array}{l}\text { The professor formulates questions through } \\
\text { educational tools, leading students through a } \\
\text { phase of analysis, reflection, and } \\
\text { understanding of previously } \\
\text { transmitted knowledge. }\end{array}$ \\
\hline $\begin{array}{l}\text { Collaborative } \\
\text { practice }\end{array}$ & $\begin{array}{l}\text { Collaborative } \\
\text { activities }\end{array}$ & $\begin{array}{l}\text { The professor develops skills and } \\
\text { competencies in the students through } \\
\text { practice and teamwork. }\end{array}$ \\
\hline Summative assessment & Evaluation activities & $\begin{array}{l}\text { The professor includes different types of } \\
\text { evaluation activities. }\end{array}$ \\
\hline $\begin{array}{l}\text { Engagement and } \\
\text { students' reflections }\end{array}$ & $\begin{array}{l}\text { Closing } \\
\text { activities }\end{array}$ & $\begin{array}{l}\text { The professor closes the topic seen in class } \\
\text { and connects it to the topic of the } \\
\text { next session. }\end{array}$ \\
\hline
\end{tabular}

The design of the professor-hologram sessions is enhanced by introducing students to an environment that allows a state of flow for an optimal experience. The five dimensions of flow state are enjoyment, concentration, challenge, control, and curiosity [9]. Except for control, these dimensions impact the distortion of time and frequency of use in the digital environment, causing students to remain immersed, achieve more cognitive absorption, and improve their focus and attention.

\subsubsection{Technology}

The Technological Learning Ecosystem of the Telepresence with Hologram Effect can be represented by the following diagram of technology layers (Figure 2).

i. Base technology: Allows recreation of face-to-face classes' natural dynamics by producing a hologram accompanied by complementary technology and learning support tools. The base technology infrastructure allows visualizing the professor's image in the anatomically correct dimensions, transmitting the audio and video (Figure 3), and projecting the hologram to multiple receiving rooms (Figure 4). Video conferencing tools transmit to different rooms simultaneously. In the transmitting room, a black background enables the illusion that the professor is in the students' site. The transmitting room also contains two monitors to view the content and the students in the receiving rooms, a microphone, and an audio system for teacher-student communication. In the receiving room (Figure 4), the students see the professor's projected image. On the monitors, they can see the content and their classmates in other rooms. The audio system and cameras support the experience that feels like a face-to-face class.

ii. Complementary technology: A Learning Management System (LMS) supports the course design, delivery, and maintenance of the platform's development.

iii. Specialized technology: Includes tools, computer languages, labs, and equipment used to develop specialized disciplinary skills.

iv. Learning support tools: For students to acquire and expand basic knowledge in a subject and to understand processes, develop skills, relate, and integrate knowledge, we used mobile devices, digital tools, and apps such as Chatbot Professor Atom, 
ART3D augmented reality, Explain Everything, Padlet, Kahoot, Socrative, Quizzies, and Edpuzzle.

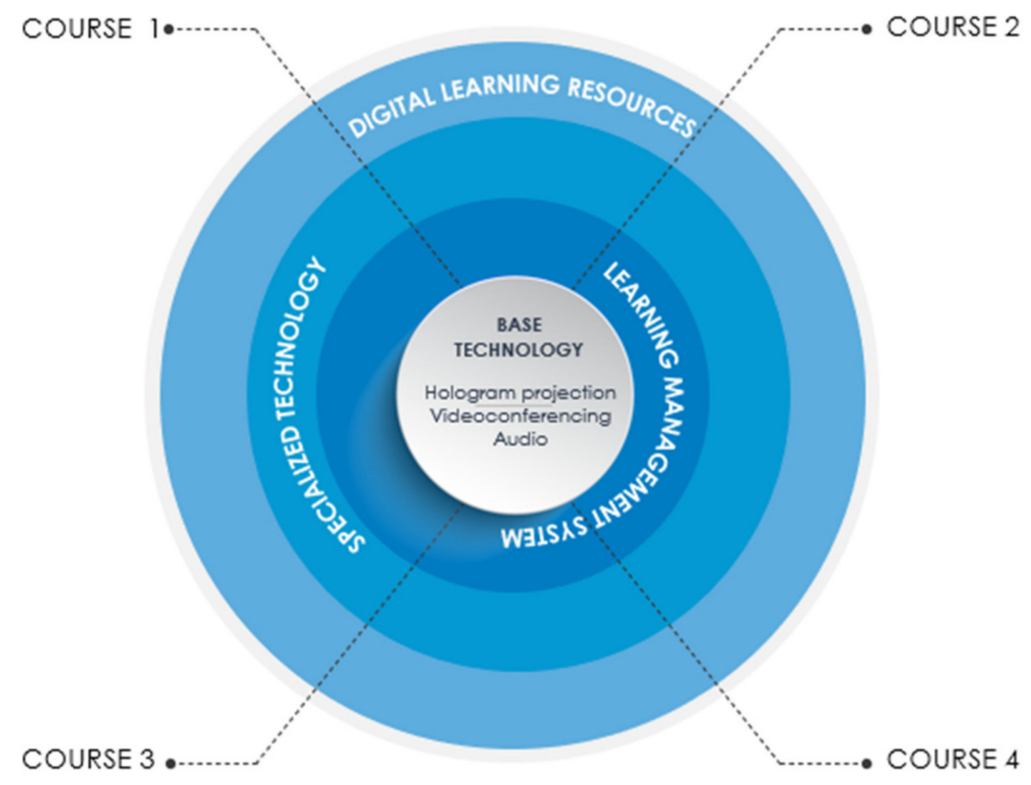

Figure 2. Diagram of layers of the Technological Learning Ecosystem of the Telepresence with Hologram Effect.

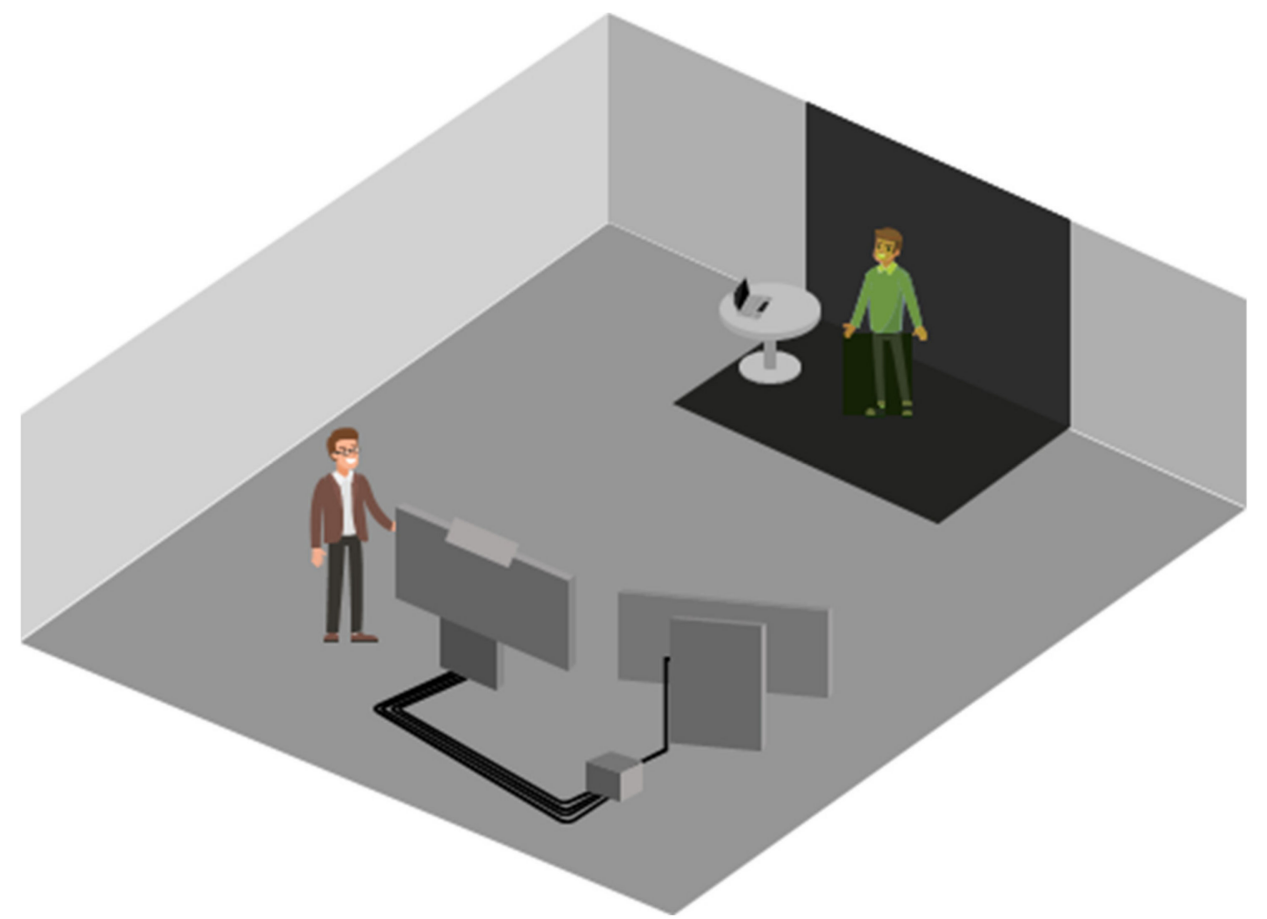

Figure 3. Transmitting room with a black background. 


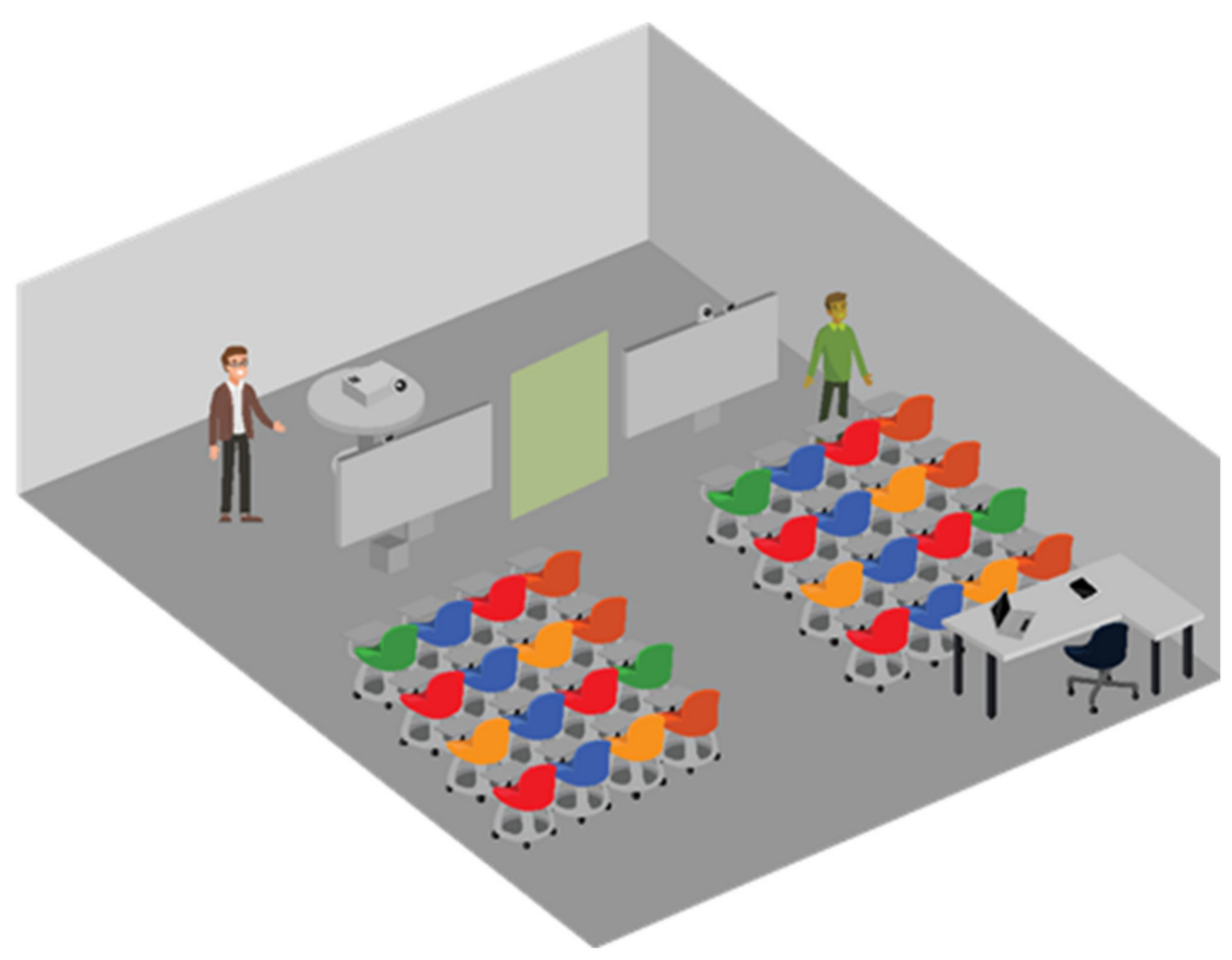

Figure 4. Receiving room.

These learning support tools combine in an educational scenario where technology is the vehicle for transmitting educational experiences. The professor decides the desired learning outputs and appropriations of knowledge, designs the class, and plans the accompanying technology.

The Technological Learning Ecosystem of the Telepresence with Hologram Effect facilitates the educational strategy in three phases: (a) deciding the Learning Management System; (b) selecting the specialized technology, and (c) developing their digital learning resources.

The introduction of Information and Communication Technology (ICT) inside a learning environment must go hand-in-hand with a clear pedagogical objective, a specified problem to solve, and the steps required to achieve the stated purpose [15].

\subsubsection{Educational Resources}

Another component is the educational resources or digital learning resources (DLR). The students' technological skills require teachers to adapt their teaching designs and methodologies to the new realities of student abilities, interests, and learning styles. An essential component in the educational experience model is the use of digital learning resources. Learning with DLR occurs in a highly different context from traditional learning, where human interactions are mediated. The technology facilitates the transmission of concepts and knowledge to students. Because of this new environment where the learner finds himself alone in front of the machine, the teacher must pay careful attention to the quality of the digital content presented when designing interactive, collaborative activities [19,20]. Some DLRs used are interactive presentations, videos, simulators, 3D and augmented reality, educational chatbots, and virtual labs (Table 2). 
Table 2. Digital learning resources and educational outputs intended.

\begin{tabular}{|c|c|c|c|c|}
\hline $\begin{array}{l}\text { Educative } \\
\text { Intention }\end{array}$ & $\begin{array}{l}\text { Digital Learning } \\
\text { Resources }\end{array}$ & $\begin{array}{l}\text { Learning } \\
\text { Output }\end{array}$ & $\begin{array}{l}\text { Type Of } \\
\text { Evidence }\end{array}$ & Interaction \\
\hline Icebreakers & $\begin{array}{l}\text {-Kahoot } \\
\text {-Menti }\end{array}$ & Answer & $\begin{array}{c}\text { Motivation and } \\
\text { engagement }\end{array}$ & Individual \\
\hline $\begin{array}{c}\text { Share } \\
\text { knowledge }\end{array}$ & $\begin{array}{l}\text {-Explain } \\
\text { Everything } \\
\text {-Simulators } \\
\text {-Interactive } \\
\text { presentations } \\
\text {-Chatbot } \\
\text {-APP }\end{array}$ & $\begin{array}{l}\text { Contents } \\
\text { presented by the } \\
\text { professor } \\
\text { through } \\
\text { technological } \\
\text { resources }\end{array}$ & $\begin{array}{l}\text { Questions and } \\
\text { knowledge } \\
\text { application }\end{array}$ & $\begin{array}{l}\text { Professor- } \\
\text { student }\end{array}$ \\
\hline Interactive & $\begin{array}{c}\text {-Kahoot } \\
\text {-Menti } \\
\text {-Chatbot } \\
\text {-Art3D for } \\
\text { augmented reality }\end{array}$ & $\begin{array}{c}\text { Analyze, } \\
\text { evaluate, and } \\
\text { create }\end{array}$ & $\begin{array}{c}\text { Motivation, } \\
\text { engagement, } \\
\text { and knowledge } \\
\text { application }\end{array}$ & Individual \\
\hline Collaborative & -Google Drive & $\begin{array}{l}\text { Analyze and } \\
\text { apply }\end{array}$ & $\begin{array}{l}\text { Activities and } \\
\text { projects }\end{array}$ & In teams \\
\hline $\begin{array}{c}\text { Closure/ } \\
\text { evaluation }\end{array}$ & $\begin{array}{l}\text {-Kahoot } \\
\text {-Menti }\end{array}$ & Evaluate & Quizzes & Individual \\
\hline
\end{tabular}

\subsubsection{Interaction}

In videoconferencing, it is generally recommended to redesign student interactions and collaboration with new kinds of interactive educational technologies and asynchronous collaboration as compared to traditional teaching [21]. The interactions that emerged within the model are: (i) teacher-student (multi-site), (ii) campus learning community, and (iii) intercampus learning community.

Agile teacher-student interactions are achieved naturally: the student raises his or her hand to participate in real-time. The professors communicate with the students using their names as if they were physically in the classroom, creating an emotional bond. The productive learning occurs through conversations among students and faculty, creating knowledge together, in real-time, without physically being in the same place [22].

Campus learning community interactions are carried out through activities within the classroom, where the students work on several activities, projects, or experiments with their local peers as if the teacher were there. Educators are challenged to leverage available media-rich, synchronous technologies to facilitate real-time interactions among remote and on-campus learners and teachers [23].

Intercampus learning communities are where students share knowledge with their peers in real-time through competitions and collaborations between campuses. The sense of community created among participants during these interactions in online learning positively affects the students [24].

In our model, communication is assisted and occurs synchronously (in real-time) and multipoint (between the transmitting room and the connected receiving rooms). The different roles are coordinated to guarantee the experience's quality during the Telepresence with Hologram Effect sessions. (A professor and a transmission coordinator are in the transmitting room and a facilitator in the receiving room). Technological backup is on hand if there is a problem with technology (Figure 5). 


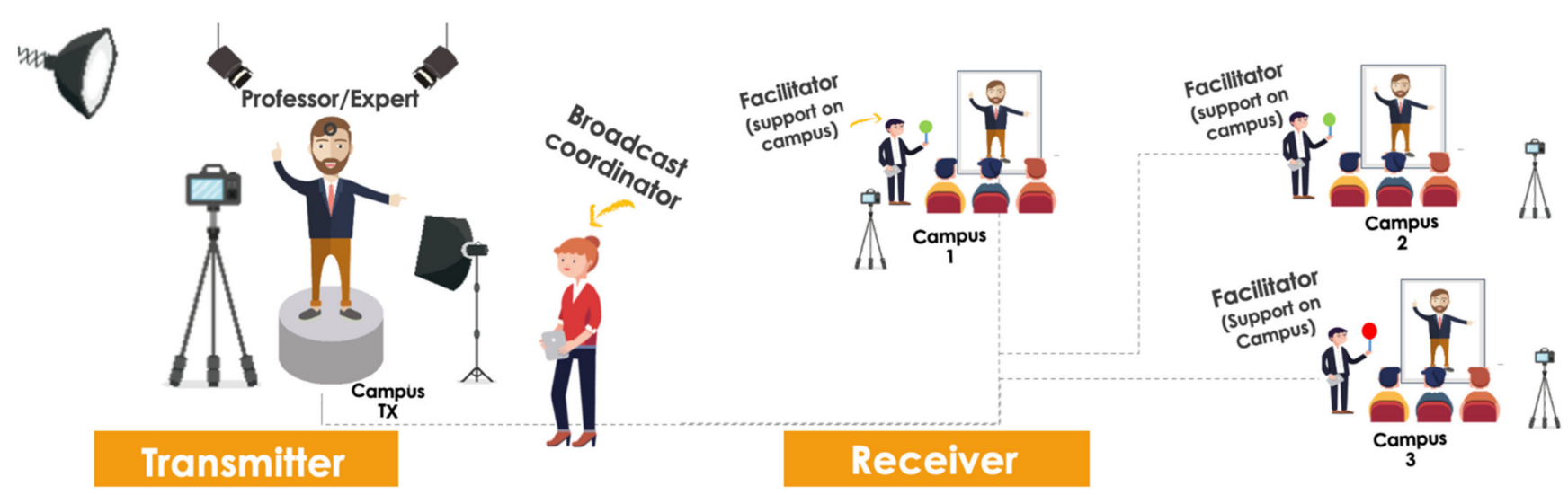

Figure 5. Diagram of the Experience of Telepresence with Hologram Effect.

During the transmission, the professor establishes warm and friendly interactions with the students to convey closeness. The communication is multi-room, but the professor maintains the communication protocol, continuously checking that the students participate in all sites.

This Technological Ecosystem of the Telepresence with Hologram Effect Model facilitates students' interactions with the hologram teacher to be as close as a physical interaction. This interaction seems to confirm that holograms are among the most effective tools inside virtual environments in providing social presence. The students feel they are learning when they feel comfortable interacting with the virtual entity, in this case, the holographic teacher [15].

During the transmission, the broadcast coordinator supports and assists the professor with the activities. Their duties include (i) establishing the initial broadcast connection; (ii) setting up the broadcasting room; (iii) testing the audio, video, and supporting materials; and (iv) communicating to the professor about the activities in the reception rooms.

\subsection{Implementation at Tecnologico de Monterrey}

Tecnologico de Monterrey has distinguished itself by promoting educational innovation while facing the challenges of a multi-campus educational system ( 25 campuses). It promotes innovative educational projects created by the professors to benefit the entire institution. Thus, our holographic courses have been implemented on 11 campuses, two of them capable of transmitting and receiving, and nine receiving centers.

\section{Method}

In this research, we chose Strauss and Corbin's representation of Grounded Theory (GT) [25]. It allows the strategic analysis of participants' perceptions, feelings, and opinions, and it links empirical data with theory $[26,27]$. We followed the Grounded Theory design to analyze and understand the data (Figure 6):

\subsection{Participants}

Theoretical sampling is used as the process of selecting incidents, slices of life, periods, or people based on their potential manifestation or representation of significant theoretical constructs [28]. This interpretation was applied to this research.

The total population of this study was 567 students taking seven courses (three Engineering, three Business, and one Architecture) from August to December of 2019. They were between 17 and 20 years of age in different semesters and from different campuses throughout Mexico. Out of the 567 students, 194 (34\%) responded (Table 3). 


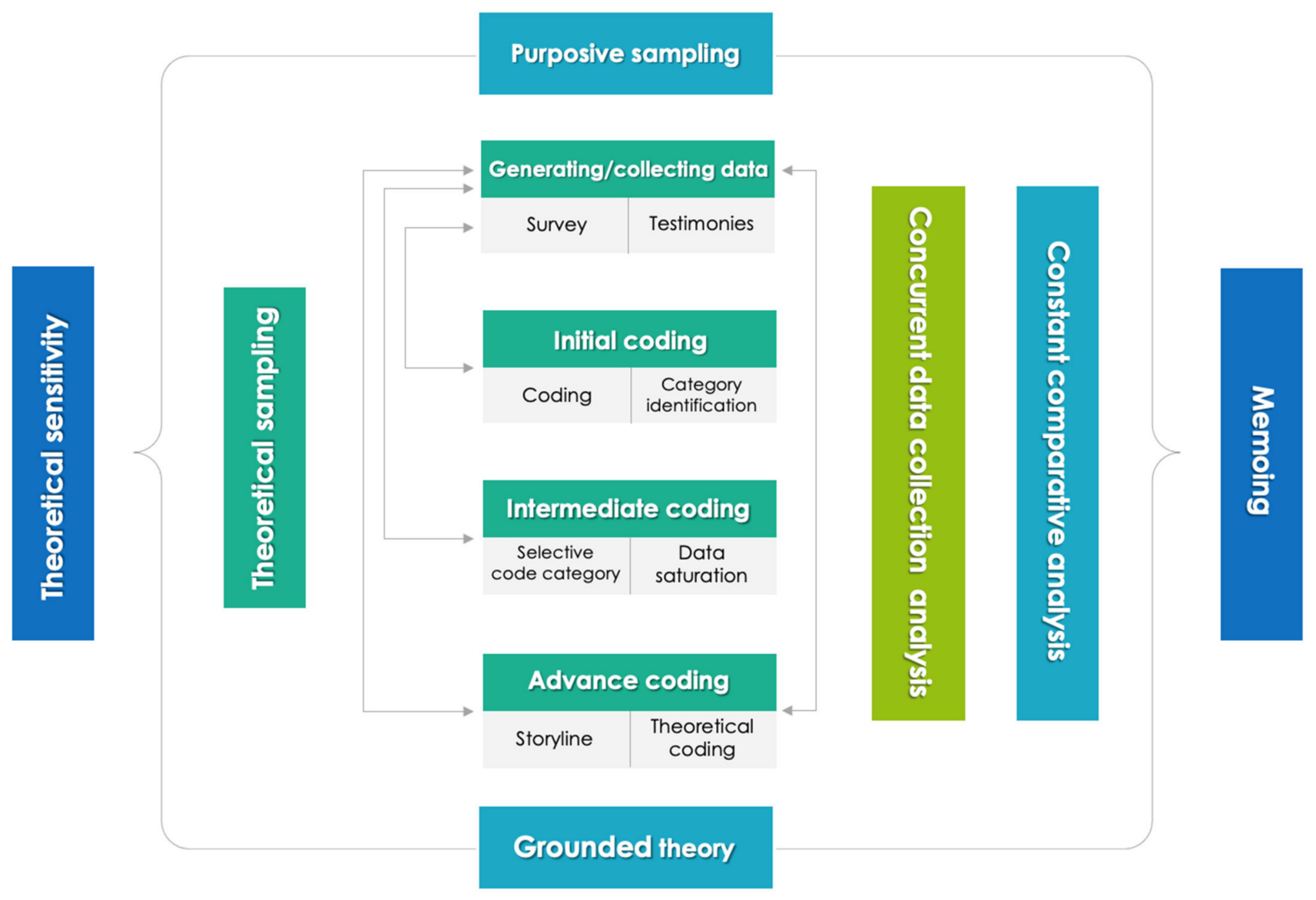

Figure 6. Grounded Theory design applied to this research.

Table 3. Participants and courses.

\begin{tabular}{ccc}
\hline \multicolumn{1}{c}{ Students 567/Responses 194 } \\
\hline Course & $\begin{array}{c}\text { Number of } \\
\text { Students }\end{array}$ & Responses \\
\hline Star Expert & & 32 \\
Physics 1 & 32 & 39 \\
Mathematics 1 & 58 & 19 \\
Financial Modeling Programming & 55 & 35 \\
Prospective and History of Industrial Design & 123 & 10 \\
Star Guest & & 45 \\
Physics 2 & 86 & 14 \\
Entrepreneurial Leadership & 133 & 194 \\
Marketing and Creativity & 80 & \\
Grand Total & 567 & \\
\hline
\end{tabular}

\subsection{Data Collection}

An instrument was designed to collect data based on the research questions: (1). How do students in telepresence-with-hologram courses evaluate the educational experience? (2). What characteristics of telepresence-with-hologram courses are meaningful to students?

The researchers chose an anonymous questionnaire (Table 4) as the instrument applied in each course. The questionnaire followed Glaser's guidelines for an open-question instrument prompting more detail [29]. The questionnaire had four open questions and one closed question with a 1 to 5 Likert scale. The participants were encouraged to discern the courses' significant characteristics and suggest the areas of opportunity to improve the Technological Ecosystem for the Telepresence with Hologram Effect Model (Figure 1). 
Table 4. Questionnaire.

\begin{tabular}{llr}
\hline \multicolumn{1}{c}{ Question } & Type of Question \\
\hline $\begin{array}{l}\text { 1. } \\
\text { In three words, describe how you found this } \\
\text { learning experience. }\end{array}$ & Open \\
\hline 2. $\quad$ In general, how do you evaluate this experience? & $\begin{array}{c}\text { Likert scale 1-5 } \\
\text { in increasing preference }\end{array}$ \\
\hline 3. $\quad \begin{array}{l}\text { Did you like something specific about the experience? Tell } \\
\text { us what it was. }\end{array}$ & Open \\
\hline 4. $\quad$ Would you change anything about the experience? Tell & Open \\
\hline 5. & Do you want to tell us anything else about this experience? & Open \\
\hline
\end{tabular}

The ethical issues, including privacy and confidentiality, were considered in the study. The instructions given by the professors to the students explained that the questionnaire was designed to improve their learning experience in future sessions and that it was anonymous.

\section{Analysis}

\subsection{Data Analysis}

Coding is an analytical process used to identify concepts, similarities, and conceptual recurrences in data; it is the pivotal link between collecting or generating data and developing a theory that explains the data [30]. Furthermore, Grounded Theory involves formulating theory from data systematically obtained from social research [31]. In this research, the intention was to explore the students' opinions.

\subsection{Open Coding}

Grounded Theory aims to account for a pattern of behavior relevant to those involved [32]. Along that line, in our work, the student opinions considered significant in each questionnaire were highlighted and set apart as essential ideas and comments. The information was read and analyzed several times and discussed among the researchers to reach a consensus. Continuous comparative analysis of data must be used to find commonalities and variations $[27,33]$.

In open coding, the main words or groups of words are identified and labeled. After this part of the process, the initial coding is separated into common categories. The participants' 194 written responses were coded generally. Then, seven primary categories were identified, namely: (a) recreation of face-to-face class dynamics; (b) professors renowned in their disciplines; (c) professor-student interactions; (d) campus and intercampus learning community interactions; (e) class design; (f) class content, and (g) use of complementary technology (digital learning resources).

\subsection{Intermediate Coding}

Initial coding fragments the data, and intermediate coding transforms primary data into more abstract concepts, allowing the theory to emerge from the data [26]. During this analytic stage, the process of reviewing categories and identifying possible sub-categories occurs, and the properties or dimensions of the developed categories are refined.

The 194 responses from the participants were coded. As stated above, the seven primary categories identified were the following: (a) recreation of face-to-face class dynamics; (b) professors renowned in their disciplines; (c) professor-student interactions; (d) campus and intercampus learning community interactions; (e) class design; (f) class content, and (g) use of complementary technology (digital learning resources) (see Figure 7). The seven 
primary categories were linked to the four main components of the Technological Ecosystem for the Telepresence with Hologram Effect Model (Figure 1) and the characteristics designed to be perceived by the students.

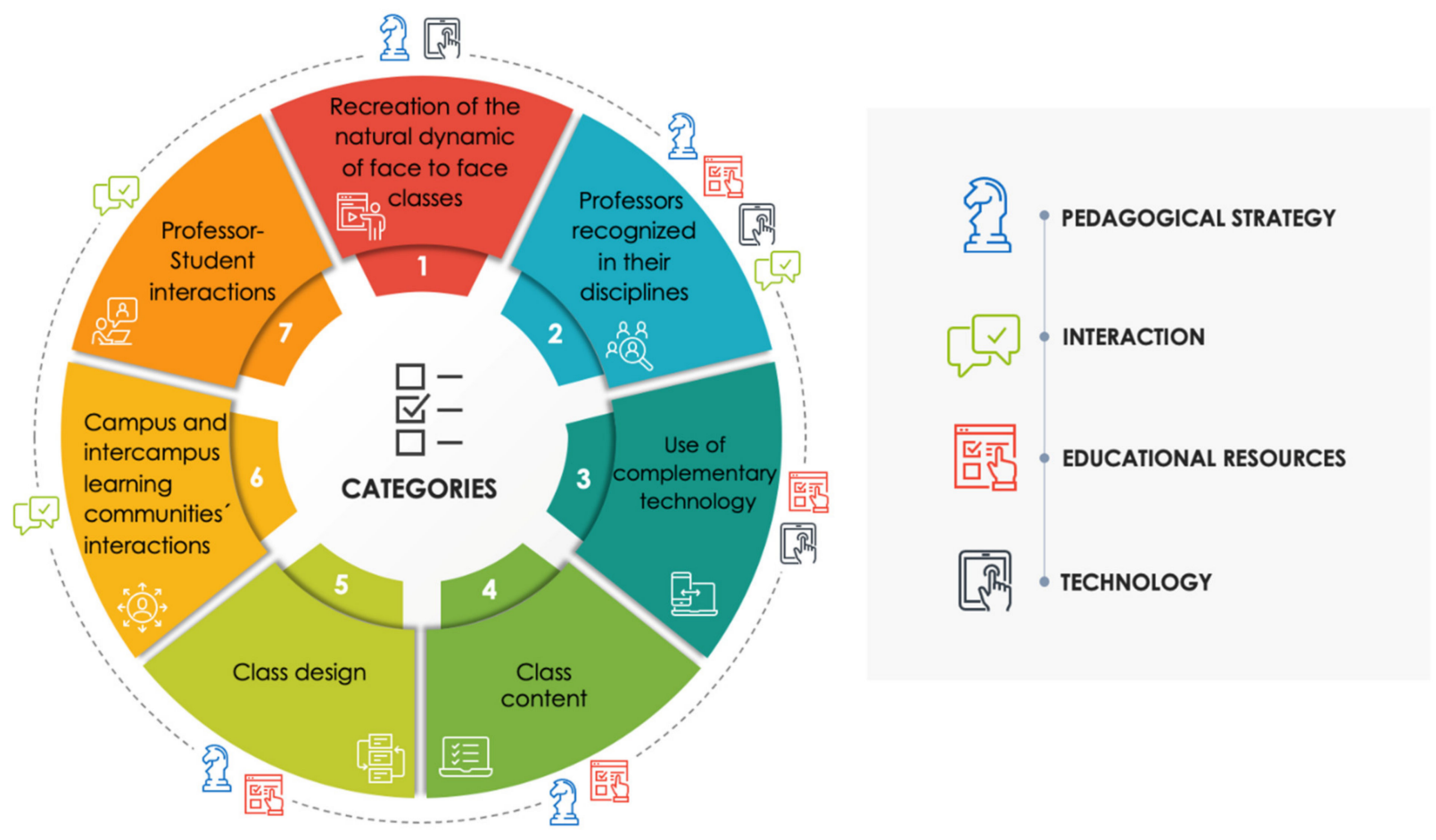

Figure 7. Primary categories.

Continuous comparative analysis was used to find commonalities and variations [31], and then the responses analyzed and categorized were refined and reduced. Straus and Corbin also declare that data is broken down into discrete parts, closely examined, and compared for similarities and differences during the process. Then, the categories are analyzed over and over again [25]. The process of categorization is described below:

We found that class design and class content should be integrated into one classdesign-and-content category. This is supported by McAlpine's research, which affirms that class design and class content are complementary elements of instruction and delivery by the professor [18].

The responses regarding the use of complementary technology were re-categorized into "recreating face-to-face natural class dynamics." The professor projected from a distance has flexibility during the class session and is at ease; the students feel accompanied by the professor at all times. These essential dynamics lead students into the state of flow involving curiosity, challenge, enjoyment, and concentration [9]. (These elements help both in-person and telepresence-with-hologram classes.)

Finally, the categories of professor-student interactions, campus learning community interactions, and intercampus learning community interactions were combined into one global category called "professor-student and campus and intercampus learning community interactions." Interactions at different levels are crucial for students' motivation and success in their distance education courses [34].

The students' responses revealed differentiating characteristics in what they highly valued in the Technological Ecosystem for the Telepresence with Hologram Effect Model. The authors found that the students highly valued one characteristic planned in the model: the intercampus learning community interactions. On the other hand, the authors also found two new characteristics that were not intended but were also highly valued by the students: the professors' experience in their fields of study and the educational resources used. When contrasting all the categories, four final ones emerged: (a) recreating the 
natural dynamics of face-to-face classes; (b) professors renowned in their disciplines; (c) professor-student and campus and intercampus learning community interactions, and (d) class design and content.

\subsection{Advanced Coding}

In the intermediate coding, all the categories found in the participants' responses were discussed and analyzed in the light of Grounded Theory, fragmented into pieces, and relocated into the final categories. The final categories and the responses from the participants are shown below (Table 5):

Table 5. Categories.

I Liked the Experience Count of "I Liked the Experience."

(a) Recreating the natural dynamics of face to face classes

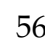

(b) Professors renowned in their disciplines

(c) Professor-student and Campus and Intercampus learning community interactions

(d) Class design and content No (I did not like the experience.)

No answer

Grand Total

Advanced coding is the technique used to facilitate the integration of the final Grounded Theory [35]. These authors promote storyline technique and theoretical coding to advance analysis and theoretical integration [26,35].

For this research, we chose the storyline technique. The storyline is a strategy for facilitating integration, construction, formulation, and presentation of research findings to produce a coherent Grounded Theory [35].

In the following section, the final categories are presented with the participants responses, and the comments are analyzed extensively:

(a) Recreating the natural dynamics of face-to-face classes. For the student, the educational experience of the telepresence courses with technological infrastructure gives them a combined sense of innovation and comfort when seeing their teacher's life-size image. In this experience, the classes are boosted by the dynamics and interconnections of several campuses. The students expressed in their comments:

"For me, the telepresence class is very comforting. It has been one of my favorite classes in my time at Tec (Tecnologico de Monterrey). It is innovative, and that makes you want to participate and attend classes more."

"Instead of just being in an online class, I liked that we could see the teacher in $3 D$ as if he were here."

"I liked how dynamic the avatar classes were.

It looks like Star Wars."

"It was very innovative and modern, the way of teaching several campuses at the same time."

"I like that technological tools are used to shorten distances and provide valuable learning resources within reach."

In these first comments, one discerns how the student perceives the setting and the educational possibilities. However, delving deeper, the students describe an engaging, innovative class and like the hybrid experience.

Students also appreciated using technology to shorten distances and recreate a face-toface classroom environment in a hybrid model. In this experience, the student comes to the 
classroom, greets their classmates and professor, works in teams or individually, and has instant, in-person support from their classmates. Although the professors are projected in a hologram, they have immediate, direct, and real-time interactions with the students. The students also benefit from the help of the facilitator, who answers simple questions or channels difficult ones to the projected expert professor. Students can also participate in challenges and activities with classmates from their campus and other campuses, fostering healthy collaboration that benefits learning.

(b) Professors renowned in their disciplines. Students appreciated their professors' and expert guests' knowledge and experience. The guest speakers were a strategic link to different organizations. The students commented:
"The documents shared by Professor Martinez were beneficial."
"I liked how the teacher made the class dynamic. Some teachers make the class very difficult, but Professor Adriana provided an excellent experience."
"I liked the experience of taking classes with professors and guests."
"The advantage of having classes with well-known speakers with an exciting career path and usually a hectic schedule."

Students highly value that professors or guests share their knowledge acquired through years of experience in their fields. They discuss investigations, anecdotes, and solutions to typical or specific cases that cannot be found in textbooks or class materials. Some guests are very busy people, and students greatly appreciated that the experts took the time to teach their class to enrich their learning. The guests give the students a strategic connection with the real world. They can leverage the Technological Ecosystem for the Telepresence with Hologram Effect Model to present themselves attractively and enjoy the session.

(c) Professor-student and campus and intercampus learning community interactions. A distinctive feature of telepresence courses is the ability to interact with students from other campuses. Students value this network of interactions. Their comments included:
"Being with students from other campuses at the same time adds a lot of diversity."
"Being able to interact with several campuses at once, listening to their questions and opinions."
"Knowing that I share classes with five different campuses makes it more competitive."
"Being able to interact with students from other campuses and seeing how they analyze the topics differently."

In these significant interactions, students appreciated the diversity, the ability to listen, analyze the opinions of their classmates, and perceive this experience as part of developing their competencies. Their comments describe how they perceive and absorb the experience in their professional training.

(d) Class design and class content. The students expressed their opinions about the contents of their courses in the telepresence ecosystem:

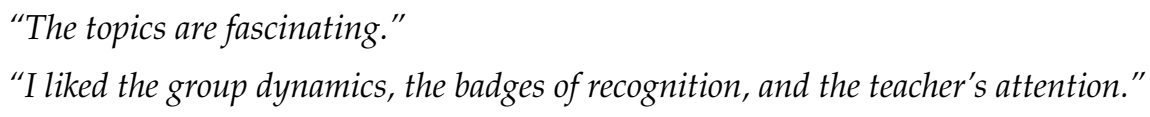

"The topics are fascinating."

"I liked the group dynamics, the badges of recognition, and the teacher's attention."

The students identified what they found exciting and the attractiveness of the class dynamics. They even mentioned that the badges were a tool of the research team to connect the educational model's stages. They perceived that the professor did pass through the three layers of the technological learning ecosystem, terminating in the digital learning resources layer; the badges represented its accomplishment (see Figure 4).

\section{Discussion}

The students perceived the Technological Ecosystem for the Telepresence with Hologram Effect Model positively. They valued the four main categories of their responses: 
(a) Recreating the natural dynamics of face-to-face classes, where the students perceived their professors as being physically present in the classroom; as reference $[9,10]$ state, this phenomenon is a perceptual illusion of being present without feeling mediated by technology. The students reported feeling focused and immersed in the experience.

(b) Professors renowned in their disciplines are valued by the students. The students are instructed to reach the applications of the subject in real life; as reference [15] supports, great teachers should be in the projections, prepared and inspired to go beyond the subject with technology to encourage the students to learn and collaborate with their classmates.

(c) Professor-student and campus and intercampus learning community interactions; as reference $[23,24]$ establishes, educators are challenged to leverage available mediarich, synchronous technologies to facilitate real-time interactions among remote and on-campus learners and teachers, and they found that a sense of community created among participants during these interactions positively affects the students.

(d) Class design and content; as reference [2,6] state, blended synchronous learning still needs better student engagement and involvement in instructional activities, and. the teacher's presence is important in creating an active learning community environment that supports the students and is attentive to their needs.

\section{Limitations of the Study}

Some challenges were that in some subjects, we had fewer answers from the students, and there were also groups that we could not apply the instrument because we were in lockdown.

The weaknesses are that the survey should be applied to a larger population. Furthermore, we would like to implement the survey in other subjects of other fields to evaluate the experience. In addition, we would like to investigate the differences between the videoconference classes and the telepresence with holograms.

\section{Conclusions and Lessons Learned}

This article highlights the key elements to teach distance courses synchronously in an educational technology ecosystem and evidence that the technological ecosystem for the Telepresence with Holograms results in positive student learning outcomes in several specified courses.

In search of improving the student experience in telepresence with holograms for this research method, the authors applied Grounded Theory because it is a structured yet flexible methodology. This methodology is appropriate when little is known about a phenomenon. The aim is to produce or construct an explanatory theory that uncovers a process inherent to the substantive area of inquiry. One of the defining characteristics of Grounded Theory is that it aims to generate theory that is grounded in the data [26], which is recollected on the field. In addition, the new theory is contrasted with previous literature.

The study was centered on the students' opinions through their testimonies according to their educational experience, impressions, and learning.

Main conclusions of this research were:

(a) The quality of the technological and communication infrastructure. Priority aspects are the hologram's projection, the audio quality, and the video conferencing link, which generate an immersive environment allowing students to feel that the professor is physically in the classroom. These aspects improve student participation naturally as if they were in a face-to-face class.

(b) Professors and keynote speakers. It is crucial to select professors with excellent pedagogical experience who are willing to increase their technological skills. It is also important to have guest experts who enrich students' learning with their business and industry experiences.

(c) Professor-student and campus and intercampus learning community interactions. It is essential to have an excellent technological, operational, and communication 
protocol to guarantee the best experience and eliminate possible audio, video, and communication problems.

(d) Using different technological resources and learning techniques. It is essential to incorporate pedagogical and technological accompaniment in the first teaching sessions. This involves exploring intercampus activities, technologies, and digital educational resources.

(e) Class design and class content. For the design of the subject, one must plan each class with a script employing the four states of flow: enjoyment, concentration, curiosity, and challenge. These principles increase the probability of success of the Technological Ecosystem for the Telepresence with Hologram Effect Model.

(f) The students positively perceived the "wow" effect of the technology. From the evidence, we can affirm that when students experience our proposed model in class, they feel comfort, amazement, interest, and engagement.

As a result of this investigation, we propose adjustments in the design and implementation of the telepresence-with-hologram sessions, highlighting the following changes:

1. Increase intercampus activities and interactions.

2. Ensure that the professors designing their sessions follow the recommendations for implementing the active learning strategy with the four principles of flow: enjoyment, concentration, curiosity, and challenge.

\section{Future Research}

Regarding future research, the authors suggest that telepresence with holograms be implemented with a professor and student protection strategy. There should be adequate seating distribution and air purification in the receiving room, fewer students, and social distancing requirements observed to avoid contagion. The technological evolution will allow us to improve the video transmission of the professor's image in a tridimensional form and the image quality.

In addition, the professor's profile could be a research topic due to their extensive use of digital learning resources, their communication skills acquired through the professorhologram technology, and their extensive knowledge and expertise.

\section{Implications}

Telepresence with holograms can be helpful in other fields, like medicine, specialized training, business, aerospace, neuroscience, research, and more.

Author Contributions: Conceptualization, P.A., C.V.R.-L. and L.C.; methodology, S.T., C.V.R.-L. and L.C.; validation, P.A.; formal analysis, S.T., C.V.R.-L. and L.C.; investigation, S.T., C.V.R.-L. and L.C.; resources, S.T., C.V.R.-L. and L.C.; data curation, C.V.R.-L. and L.C.; writing-original draft preparation, C.V.R.-L., L.C., P.A. and S.T.; writing-review and editing, S.T.; visualization, S.T.; supervision, S.T.; project administration, C.V.R.-L., L.C., P.A. All authors have read and agreed to the published version of the manuscript.

Funding: This research received no external funding.

Institutional Review Board Statement: Ethical review and approval for this study was waived because the inputs to this research were taken from an anonymous survey by students.

Informed Consent Statement: Informed consent was obtained from all subjects involved in the study.

Acknowledgments: The authors acknowledge the technical support of the Writing Lab, Institute for the Future of Education, Tecnologico de Monterrey, Mexico, in the production of this work. In addition, the authors wish to acknowledge the Academic Vice-Rectory, Educational Innovation, and The School of Engineering and Sciences. The authors thank: Eduardo Luévano, Eduardo González, Manuel Zertuche, Joaquín Guerra, Omar Olmos, Beatriz Palacios, Laura Zepeda, Andrés González, and Nahún Quintero. Hologram professors: Alfonso Serrano, José Manuel Pardo, Miguel Ángel López, Roberto D. Rodríguez, Jorge Álvarez, Ana Elena Mallet, Santa Tejeda, Elvira Rincón, Ana 
María Mutio, Carlos D. Prado, Saúl Juarez, Gerardo P. Aguilar, Eduardo Theurel, Rafael C. Lozoya, Adriana Vargas, Luis Jacob Escobar.

Conflicts of Interest: The authors declare no conflict of interest.

\section{References}

1. López, H.A.; Ponce, P.; Molina, A.; Ramírez-Montoya, M.S.; Lopez-Caudana, E. Design Framework Based on TEC21 Educational Model and Education 4.0 Implemented in a Capstone Project: A Case Study of an Electric Vehicle Suspension System. Sustainability 2021, 13, 5768. [CrossRef]

2. Zilka, G.C.; Cohen, R.; Rahimi, I.D. Teacher presence and social presence in virtual and blended courses. J. Inf. Technol. Educ. Res. 2018, 17, 103-126. [CrossRef]

3. Rehn, N.; Maor, D.; McConney, A. Investigating teacher presence in courses using synchronous videoconferencing. Distance Educ. 2016, 37, 302-316. [CrossRef]

4. Divanoglou, A.; Chance-Larsen, K.; Fleming, J.; Wolfe, M. Physiotherapy student perspectives on synchronous dual-campus learning and teaching. Australas. J. Educ. Technol. 2018, 34, 88-104. [CrossRef]

5. Maboe, K.A. Use of online interactive tools in an open distance learning context: Health studies students' perspective. Health $\mathrm{Sa}$ Gesondheid 2017, 22, 221-227. [CrossRef]

6. Wang, Q.; Huang, C.; Quek, C.L. Students' perspectives on the design and implementation of a blended synchronous learning environment. Australas. J. Educ. Technol. 2018, 34, 1-13. [CrossRef]

7. Sidharta, R.; Hiyama, A.; Tanikawa, T.; Hirose, M. The Development of Multi-Depth Pepper's Ghost Display for Mixed Reality System. In Proceedings of the 16th International Conference on Artificial Reality and Telexistence-Workshops (ICAT'06), Hangzhou, China, 29 November-1 December 2006; IEEE: Piscatway, NJ, USA, 2007; pp. 115-118. [CrossRef]

8. Pantoja, G.; Mendívil, E.G.; Flores, P.G.R.; Suárez-Warden, F.; Hendrichs, N. Use of pdlc film for improving visualization of contents in holographic display under different illumination scenarios. Procedia Comput. Sci. 2015, 75, 151-160. [CrossRef]

9. Pelet, J.; Ettis, S.; Cowart, K. Optimal experience of flow enhanced by Telepresence: Evidence from social media use. Sci. Direct 2017, 54, 115-128. [CrossRef]

10. Csikszentmihalyi, M. Beyond Boredom and Anxiety; Jossey-Bass: Hoboken, NJ, USA, 2000.

11. Viberg, O.; Bälter, O.; Hedin, B.; Riese, E.; Mavroudi, A. Faculty pedagogical developers as enablers of technology-enhanced learning. Br. J. Educ. Technol. 2018, 50, 2637-2650. [CrossRef]

12. Freeman, S.; Eddy, S.L.; McDonough, M.; Smith, M.K.; Okoroafor, N.; Jordt, H.; Wenderoth, M.P. Active learning increases student performance in science, engineering, and mathematics. Proc. Natl. Acad. Sci. USA 2014, 111, 8410-8415. [CrossRef]

13. Giannakos, M.N.; Krogstie, J.; Aalberg, T. Video-based learning ecosystem to support active learning: Application to an introductory computer science course. Smart Learn. Environ. 2016, 3, 11. [CrossRef]

14. Stroh, H.R.; Sink, C.A. Applying APA's learner-centered principles to school-based group counseling. Prof. Sch. Couns. 2002, 6, 71-78.

15. Gudino, S.; Vázquez, N.R. Is holographic teaching an educational innovation? Int. J. Interact. Des. Manuf. 2020, 14, 1321-1336.

16. Jhurree, V. Technology integration in education in developing countries: Guidelines to policymakers. Int. Educ. J. 2005, 6, 467-483.

17. Tan, E. Effects of two differently sequenced classroom scripts on common ground in collaborative inquiry learning. Instr. Sci. 2018, 46, 893-919. [CrossRef]

18. Mcalpine, L. Designing learning as well as teaching: A research-based model for instruction that emphasizes learner practice. Act. Learn. High. Educ. 2004, 5, 119-134. [CrossRef]

19. Camilleri, M.A.; Camilleri, A.C. Digital learning resources and ubiquitous technologies in education. Technol. Knowl. Learn. 2017, 22, 65-82. [CrossRef]

20. El Mhouti, A.; Nasseh, A.; Erradi, M. How to evaluate the quality of digital learning resources. Int. J. Comput. Sci. Res. Appl. 2013, 3, 27-36.

21. Weitze, C.L.; Ørngreen, R. The Global Classroom Model Simultaneous Campus-and Home-Based Education Using Videoconferencing. Electron. J. E-Learn. 2014, 12, 215-226.

22. Stewart, A.R.; Harlow, D.B.; DeBacco, K. Students' experience of synchronous learning in distributed environments. Distance Educ. 2011, 32, 357-381. [CrossRef]

23. Bower, M.; Kennedy, G.; Dalgarno, B.; Lee, M.J.; Kenney, J.; De Barba, P. Use of media-rich real-time collaboration tools for learning and teaching in Australian and New Zealand universities. In Ascilite; Academia: San Francisco, CA, USA, 2012 ; pp. 133-144.

24. Weiser, O.; Blau, I.; Eshet-Alkalai, Y. How do medium naturalness, teaching-learning interactions and Students' personality traits affect participation in synchronous E-learning? Internet High. Educ. 2018, 37, 40-51. [CrossRef]

25. Strauss, A. Corbin, J. Basics of Qualitative Research: Grounded Theory Procedures and Technique, 2nd ed.; Sage: Thousand Oaks, CA, USA, 1998

26. Chun Tie, Y.; Birks, M.; Francis, K. Grounded theory research: A design framework for novice researchers. SAGE Open Med. 2019, 7, 2050312118822927. [CrossRef] [PubMed]

27. Mahdiuon, R.; Masoumi, D.; FARASATKHAH, M. Quality improvement in virtual higher education: A grounded theory approach. Turk. Online J. Distance Educ. 2017, 18, 111-131. [CrossRef]

28. Patton, M.Q. Qualitative Research and Evaluation Methods, 2nd ed.; Sage Publications: Thousand Oaks, CA, USA, 2001. [CrossRef] 
29. Glaser, B.G. Jargonizing: Using the Grounded Theory Vocabulary; Sociology Press: Mill Valley, CA, USA, 2009.

30. Charmaz, K. The power and potential of grounded theory. Med Sociol. Online 2012, 6, 2-15.

31. Glaser, B.G.; Strauss, A.L.; Strutzel, E. The discovery of grounded theory: Strategies for qualitative research. Nurs. Res. 1968, 17, 364. [CrossRef]

32. Glaser, B.G. Theoretical sensitivity. In Advances in the Methodology of Grounded Theory; Sociology Press: Mill Valley, CA, USA, 1978.

33. Creswell, J.W. Educational Research: Planning, Conducting, and Evaluating Quantitative and qualitative Research, 4th ed.; Prentice Hall: Upper Saddle River, NJ, USA, 2007.

34. Alhih, M.; Ossiannilsson, E.; Berigel, M. Levels of interaction provided by online distance education models. EURASIA J. Math. Sci. Technol. Educ. 2017, 13, 2733-2748. [CrossRef]

35. Birks, M.; Mills, J. Grounded Theory: A Practical Guide, 2nd ed.; SAGE: London, UK, 2015. [CrossRef] 